Rodolfo Andrade de Gouveia Vilela ${ }^{1}$

Erivelton Fontana de Laat ${ }^{2}$

Verônica Gronau Luz ${ }^{3}$

Alessandro José Nunes da Silva ${ }^{4}$

Mara Alice Conti Takahashi ${ }^{4}$

\footnotetext{
${ }^{1}$ Universidade de São Paulo, Faculdade de Saúde Pública, Departamento de Saúde Ambiental. São Paulo, SP, Brasil.

${ }^{2}$ Universidade Estadual do Centro Oeste. Irati, PR, Brasil.

${ }^{3}$ Universidade Federal da Grande Dourados, Faculdade de Ciências da Saúde, Curso de Nutrição. Dourados, MS, Brasil.

${ }^{4}$ Centro de Referência em Saúde do Trabalhador de Piracicaba. Piracicaba, SP, Brasil.
}

Contato:

Rodolfo Andrade de Gouveia Vilela E-mail:

ravilela@usp.br

O estudo é baseado em tese de doutorado de Erivelton Fontana de Laat intitulada Trabalho e risco no corte manual de cana-de-açúcar: a maratona perigosa nos canaviais, defendida em 2010 no Programa de Pós-Graduação em Engenharia de Produção da Universidade Metodista de Piracicaba. Santa Bárbara d'Oeste, SP, Brasil.

Resumo da tese foi apresentado no International Congress on Environmental Health ICEH 2012 - Lisboa, Portugal.

Projeto de pesquisa financiado pela Fundação de Amparo à Pesquisa do Estado de São Paulo - FAPESP - processo $n^{\circ} 06 / 51684-3$.

Os autores declaram não haver conflitos de interesses.

Recebido: 05/03/2013

Revisado: 09/09/2014

Aprovado: 11/11/2014

\section{Pressão por produção e produção de riscos: a "maratona" perigosa do corte manual da cana-de-açúcar}

\author{
Pressure for production and risks production: the dangerous \\ 'marathon' of sugar cane manual cutting
}

\begin{abstract}
Resumo
Introdução: o setor sucroalcooleiro vem apresentando franca expansão no país nos últimos anos, contando com cerca de 400 usinas processadoras, mais de 1 mil indústrias de suporte e gerando 1 milhão de empregos diretos. Objetivo: compreender, no trabalho dos cortadores de cana-de-açúcar, os determinantes organizacionais que intensificam a carga de trabalho e afetam a saúde dos trabalhadores. Métodos: utilizou-se a Análise Ergonômica do Trabalho, integrada com a avaliação de aspectos fisiológicos e ambientais. Foram avaliados 40 trabalhadores de uma turma de cortadores escolhida por conveniência. A sobrecarga térmica foi monitorada, bem como a frequência cardíaca e a produção diária de cada trabalhador. Resultados: o corte manual da cana durou em média 8 horas diárias de trabalho, com ritmos intensos, alta frequência de movimentos repetitivos e exigências posturais inadequadas, associadas a condições insalubres. Conclusão: o efeito nocivo das variáveis fisiológicas e do aumento da carga cardiovascular foi demonstrado. O ritmo de trabalho é acelerado por medidas gerenciais e organizacionais, com destaque para o pagamento por produção, responsável pelo aumento do desgaste físico dos trabalhadores, ultrapassando seus limites fisiológicos. Recomenda-se, dentre outras medidas, a alteração na forma de remuneração do trabalho no corte manual de cana.
\end{abstract}

Palavras-chave: cana-de-açúcar; ergonomia; condições exaustivas de trabalho; saúde do trabalhador.

\begin{abstract}
Background: the sugar-cane sector is quickly expanding in Brazil in the recent years accounting for about 400 processing plants, more than a thousand support industries and generating one million direct jobs. Objective: to understand the organizational determinants that lead to the intensification of the workload and affect the health of manual sugar-cane cutters. Methods: we performed the Work Ergonomic Analysis integrated into the assessment of physiological and environmental aspects. A team of 40 sugar-cane cutters was chosen by convenience. Each worker was assessed for thermal overload, as well as the heart rate and daily production. Results: the findings showed that sugar cane manual cutting consists on average of 8 hours of daily activity, with intense work rhythms, high frequency of repetitive movements and inadequate postural requirements associated with unhealthy working conditions. Conclusion: The harmful effect of the physiological variables and the increase of cardiovascular load were demonstrated. The work pace is accelerated by managerial and organizational measures, especially the payment by production, responsible for increasing the physical exhaustion of workers and inducing them to exceed their physiological limits. It is recommended, among other measures, an alteration in the form of remuneration of the sugar-cane cutters.
\end{abstract}

Keywords: sugar cane; ergonomics; exhausting working conditions; occupational health. 


\section{Introdução}

O Brasil é reconhecido, no cenário mundial, como expoente na produção de biocombustíveis, principalmente do etanol da cana-de-açúcar, atividade econômica que se constituiu, nos últimos anos, em ponto estratégico da agenda comercial brasileira.

Desde a década de 1970, com o programa Proálcool, houve uma vertiginosa expansão do plantio de cana-de-açúcar no país, sobretudo no Estado de São Paulo, que responde por $56 \%$ da produção nacional (BACCARIN; GEBARA; BORGES JUNIOR, 2011). Segundo dados da União da Indústria de Cana-de-Açúcar (2013a), apenas nesse Estado foram plantados 3.890.414 hectares de cana-de-açúcar em 2007, com aumento para 5 milhões de hectares em 2011. Em 2008/2009, em São Paulo, mais de 3 milhões de litros de etanol foram exportados (UNIÃO DA INDÚSTRIA DE CANA-DE-AÇÚCAR, 2013a). No Brasil, de acordo com dados do SEBRAE (SERVIÇO DE APOIO ÀS MICRO E PEQUENAS EMPRESAS, 2008), o cultivo dos canaviais ocupa 2,5\% da área arável do país.

Embora estratégica, a produção do etanol convive com o rudimentar modo manual de colheita da cana pelos "boias-frias", em sua maioria migrantes do Nordeste brasileiro (SILVA, 2008). Entre 1986 e 2006, a produtividade do trabalho dos cortadores de cana dobrou de 6 toneladas de cana/homem/dia para 12 toneladas cana/homem/dia, e, no mesmo período, o piso salarial da categoria decresceu de 2,5 salários mínimos para 1,2 salário mínimo (ALVES, 2008).

O processo de trabalho no corte da cana ocorre no espaço que é chamado de "eito". Esse espaço é composto basicamente por um retângulo de 8,5 metros, no qual estão dispostas cinco ruas de cana, espaçadas com 1,5 metro de distância entre uma rua e outra. É o comprimento do "eito" que indicará o ganho diário do cortador, pois ele é medido em metros lineares e multiplicado pelo valor do metro (ALVES, 2006). Concluída a leira ${ }^{5}$, o corte é finalizado com o desponte dos talos já amontoados, ação que consiste em cortar as pontas do talo, que são desprezadas porque possuem menos açúcar e muita folha. Em geral, esse trabalho é realizado com a cana queimada, tendo em vista que o fogo elimina insetos, animais peçonhentos e a palha, o que facilita a visão do material a ser cortado e a pega do feixe pelo trabalhador. No entanto, as queimadas representam elevado impacto negativo ao meio ambiente e à saúde dos trabalhadores e da população em geral (CANÇADO et al., 2006).

A monocultura açucareira vem se ajustando aos diferentes contextos econômicos, mantendo sua estrutura praticamente inalterada. O mercado de trabalho passou do regime de trabalho escravo para o trabalho assalariado, mas a manutenção dos grandes latifúndios, a dominância oligárquica e o atraso cultural contribuíram para o predomínio de relações autoritárias de trabalho e baixos níveis salariais (ALVES, 2006).

Andrade (1994) considera que a agroindústria sucroalcooleira no Brasil atinge notáveis níveis de progresso técnico, contudo, ao mesmo tempo, preserva em sua essência as formas tradicionais de expropriação da mão de obra e acentua a concentração de propriedade e renda.

Trata-se, portanto, de uma "modernização perversa" que, contraditoriamente, desenvolve novas tecnologias de processo e de produto - o etanol brasileiro é o exemplo mais conhecido desses avanços -, mas reproduz, perpetua e sofistica formas de exploração do trabalho herdadas dos tempos coloniais, marcadas pelo autoritarismo, pela inobservância, na prática, da legislação brasileira. Com isso, é muito comum as práticas do recrutamento pelos intermediários ("gatos") e as de trabalho degradante ou análogas ao trabalho escravo, como apurado pelo Ministério Público do Trabalho (MPT) e pelo Ministério do Trabalho e Emprego (MTE) (ALVES, 2009).

Diante desse cenário desalentador, vale lembrar que, apesar de a mecanização da colheita da cana-de-açúcar estar em andamento, sobretudo no Estado de São Paulo, o processo está muito longe de eliminar o trabalho humano, já que a primeira colheita deve ser feita de forma manual para não prejudicar a rebrota das mudas, além de existirem áreas não mecanizáveis devido a solos irregulares e com declives acentuados, o que demanda o corte manual. Ao contrário do que se possa pensar, o número de trabalhadores rurais no corte manual de cana só vem aumentando, passando de 335 mil em 2007 (JUTTEL, 2008) para 500 mil trabalhadores em 2010 (UNIÃO DA INDÚSTRIA DE CANA-DE-AÇÚCAR, 2013b).

Segundo Novaes (2007), critérios rígidos de seleção de pessoal são aplicados no setor canavieiro, exigindo-se a meta mínima de corte de 10 toneladas por dia por trabalhador. De 5 mil trabalhadores contratados pela usina estudada pelo pesquisador, 2 mil foram "devolvidos" para as regiões de origem no primeiro mês; cerca de 1 mil foram demitidos no segundo mês; os 2 mil restantes que permaneceram foram "campeões de produtividade", pois cortaram, até o final da safra, a produção equivalente aos 5 mil trabalhadores iniciais, alcançando índices de 20 toneladas de cana/dia e médias mensais entre 12 e 17 toneladas/dia. Segundo o autor, as usinas colocam em prática técnicas motivacionais para estimular a competição entre os trabalhadores

5 A leira é o local onde são posicionadas as canas cortadas, em montes e deitadas. 
e aumentar a produtividade do trabalho, utilizando bonificações sobre os lucros e os resultados e também premiações aos trabalhadores mais produtivos, com sorteio e doação de carros, bicicletas, televisores, rádios, refrigeradores etc. (NOVAES, 2007, p. 171-172).

Nos últimos anos, a ocorrência de 21 mortes de cortadores manuais de cana foi relatada nas safras de 2004 a de 2007, no interior de São Paulo. As mortes atingiram trabalhadores jovens, com idade entre 24 e 50 anos, migrantes de outras regiões do país (LAAT et al., 2008). As causas das mortes que constam dos atestados de óbitos são vagas, não permitindo uma análise conclusiva a respeito. Nesses atestados afirma-se que as mortes são decorrentes de parada cardíaca, insuficiência respiratória, acidente vascular cerebral (AVC) ou causas desconhecidas. Porém amigos e familiares relataram que, no período que antecedeu às mortes, os trabalhadores haviam reclamado de excesso de trabalho, dores no corpo, câimbras, falta de ar, desmaios, dentre outros sintomas (ALVES, 2006; AZEVEDO, 2007). Além dos óbitos, foi registrado também um elevado índice de acidentes na atividade de cultivo de cana-de-açúcar, com taxas de incidência de acidentes de trabalho 2,4 a 3,8 vezes maiores que a taxa nacional de incidência de acidentes de trabalho, conforme dados oficiais da Previdência Social (BRASIL, 2008).

\section{Considerações sobre o trabalho exaustivo}

Está consagrada, no campo da fisiologia, a importância das pausas para o repouso, de modo a tornar o ritmo de trabalho compatível às necessidades humanas, uma vez que elas são fundamentais para a regulação biomecânica em três aspectos essenciais para o organismo: (1) a manutenção da temperatura corpórea na faixa de 36,5 a $37^{\circ} \mathrm{C}$ (GOLDBERG, 1997; BERGERON et al., 2005; KJELLSTROM; LEMKE; HYAT, 2011); (2) a regulação da frequência cardíaca (SHAHID et al., 1999); (3) a normalização das estruturas musculoesqueléticas (ASSUNÇÃO; VILELA, 2009).

No tocante à sobrecarga térmica, Bitencourt, Ruas e Maia (2012) analisaram a condição atmosférica no dia da morte de 14 trabalhadores do corte de cana-de-açúcar no Estado de São Paulo, comparando valores das ocorrências com a série histórica (1957 a 2008) de variáveis meteorológicas, como temperatura, umidade, vento e radiação. Os autores constataram que, em 10 dos 14 casos analisados, as temperaturas observadas nos dias dos óbitos eram maiores ou iguais à média histórica estudada somada ao desvio-padrão, sendo que, em seis casos, o valor da temperatura atingiu ou ficou muito próxima do recorde histórico. É possível concluir que a condição atmosférica pode ser um fator importante a ser considerado na análise das condições gerais de trabalho dos cortadores de cana-de-açúcar.

A situação torna-se mais crítica se considerarmos que a cultura da cana tem se expandido para regiões ainda mais quentes, como o Centro-Oeste brasileiro. Esse cenário tende ainda a ser agravado pelas previsões de aumento das temperaturas, decorrentes das mudanças climáticas no plano mundial, com o aumento da média das temperaturas neste século em cerca de 2 a $4{ }^{\circ} \mathrm{C}$, se não houver o controle planetário das emissões dos gases de efeito estufa (INTERGOVERNMENTAL PANEL ON CLIMATE CHANGE, 2007).

Nessa perspectiva, as populações que trabalham em ambientes externos quentes terão esses efeitos à saúde agravados, uma vez que medidas de proteção como resfriamento e ventilação não são aplicáveis em trabalhos a céu aberto. Segundo Kjellstrom, Lemke e Hyat (2011), o método mais efetivo de controle desses riscos é a redução da produção do calor do metabolismo, por exemplo, adotando pausas maiores e mais prolongadas durante a jornada de trabalho. No entanto, o aumento desses períodos de descanso vai reduzir a produtividade diária dos trabalhadores e os resultados econômicos da produção. Para a manutenção dos mesmos índices, seria necessária a ampliação do efetivo.

No entanto, estudos têm mostrado que os equipamentos de proteção individual (EPIs) representam, muitas vezes, um risco adicional para os trabalhadores rurais. Em regiões quentes e úmidas ou secas, segundo Havenith (1999), o trabalho rural com o uso de EPI é mais insalubre quando comparado com o realizado em condições mais amenas. Um trabalhador executando uma atividade moderada, sob condições climáticas amenas, utilizando roupas leves, levaria em média 90 minutos para elevar em $1,5{ }^{\circ} \mathrm{C}$ sua temperatura corporal. Caso esse mesmo trabalhador utilizasse uma roupa impermeável e sintética, esse tempo cairia para 20 minutos.

A legislação brasileira, na Norma Regulamentadora 15 (NR 15 - atividades e operações insalubres), do MTE (BRASIL, 1978a), define o limite de tolerância de sobrecarga térmica pelo Índice de Bulbo Úmido Termômetro de Globo (IBUTG) de $25,0{ }^{\circ} \mathrm{C}$ para a exposição do trabalhador em atividade considerada pesada (fatigante), como é o caso do corte manual da cana-de-açúcar, e taxa de metabolismo superior a $415 \mathrm{Kcal}$. Para valores de IBUTG acima de $25^{\circ} \mathrm{C}$, a NR15 preconiza medidas de controle como hidratação e pausas regulares para descanso em sombra. Para valores de IBUTG de 26,0 a $27,9{ }^{\circ} \mathrm{C}$, é preconizado regime de 30 minutos de trabalho por 30 minutos de descanso.

Quando o trabalhador usa vestimentas pesadas, como luvas, botas, perneiras etc., que dificultam 
a transpiração e liberação de calor, a American Conference of Governmental Industrial Hygienists (1999) recomenda a redução de $2{ }^{\circ} \mathrm{C}$ no limite do IBUTG, ou seja, o limite de exposição, considerando a vestimenta, passa a ser IBUTG de $23,0{ }^{\circ} \mathrm{C}$. Acima desse limite de tolerância, são preconizadas as medidas de controle de descanso relatadas anteriormente. Essas informações revelam, portanto, o quanto a legislação brasileira está desatualizada na proteção social de trabalhos dessa natureza.

Quanto à frequência cardíaca, trata-se do indicador da intensidade do esforço mais utilizado devido à praticidade, à confiabilidade e ao custo relativamente baixo para sua medição (KROEMER; GRANDJEAN, 2005). Entretanto, no âmbito da saúde ocupacional e, mais especificamente, na colheita da cana-de-açúcar, tem sido pouco explorado.

A frequência cardíaca é caracterizada pelo número de vezes que o coração se contrai e relaxa, ou seja, o número de vezes que o coração bate por minuto, e pode ser subdivida em: frequência cardíaca basal, frequência cardíaca de repouso, frequência cardíaca de reserva e frequência cardíaca máxima (GOLDBERG, 1997).

A frequência cardíaca é dependente de mecanismos de controle intrínsecos, neurais e humorais, sendo o esforço físico um dos fatores que induz a mudanças nos parâmetros cardiovasculares. Seus efeitos podem ser imediatos (ajustes) ou tardios (adaptações). Durante a realização de exercícios físicos, o batimento cardíaco sofre ajustes, por exemplo, se o exercício é intenso, as necessidades de oxigênio aumentam, o que leva o coração a ter de bombear mais sangue, aumentando, portanto, a frequência de batimentos.

Em esportes de alto rendimento, que podem ser comparados ao desgaste do cortador de cana-de-açúcar, episódios de óbitos em maratonistas em atividades extenuantes, combinadas com condições ambientais agressivas (temperaturas elevadas e umidade relativa elevada ou muito baixa), estão relatados na literatura (ROBERTS, 2005; FINCH; BOUFOUS, 2008).

Dessa forma, um trabalho pode ser considerado muito leve, quando alcança uma frequência cardíaca média inferior a $75 \mathrm{bpm}$ (batimentos por minuto); leve, quando varia de 75 a $100 \mathrm{bpm}$; medianamente pesado, de 101 a $125 \mathrm{bpm}$; pesado, de 126 a $150 \mathrm{bpm}$; extremamente pesado, quando a variação está acima de 151 bpm (APUD, 1997). Esse autor, na inexistência de outras informações individuais, sugere esse parâmetro classificatório para um trabalho desenvolvido em turno de 8 horas. Já a carga cardiovascular (CCV) é o índice mais usado para avaliar o impacto fisiológico do trabalho, pois corresponde à percentagem da frequência cardíaca no trabalho em relação à frequência cardíaca máxima admitida ${ }^{6}$.

Existem recomendações em percentagem para limites de tolerância, por exemplo, 33\% da CCV (ROGERS, 1989); outro limite prudencial mais protetor que pode ser usado é de $30 \%$ da CCV, adotado em estudo com cortadores de cana africanos (LAMBERT; CHEEVERS; COOPOO, 1994). Esses autores adotaram esse limite mais restritivo porque levaram em conta as características específicas dessa atividade, na qual prevalece a exposição a altas temperaturas, umidade muito alta ou muito baixa, agravada por vestimentas de proteção que dificultam a dissipação de calor.

Kroemer e Grandjean (2005) recomendam que o limite da Frequência Cardíaca Média (FCM) durante a jornada de trabalho seja de no máximo $35 \mathrm{bpm}$, acima da Frequência Cardíaca em Repouso (FCR), como uma referência a ser obedecida para atividade contínua de trabalho para homens.

Assunção e Vilela (2009) apresentaram um panorama de como os fatores de risco biomecânicos agem sobre o organismo em condições de repetitividade, em atividades dinâmicas de alta repetição, nas quais são frequentes as contrações excêntricas (contrações musculares com alongamento do músculo). Nessas condições, podem ocorrer danos musculares que somente serão reversíveis se houver pausas regulares para a recuperação dessas estruturas. Quando a musculatura é hipersolicitada, sob o ponto de vista fisiológico, ocorrem modificações bioquímicas, tais como: acúmulo de lactato, insuficiência de glicogênio e modificações das concentrações iônicas intra e extracelulares. Para as autoras, a forma de organização do trabalho que não permite que o trabalhador utilize sua inteligência corporal e situações que dificultam o exercício de pausas ou a desaceleração do ritmo caracterizam obstáculo à recuperação das fibras musculares e à normalização das estruturas musculoesqueléticas. A Norma Regulamentadora 17 (NR 17 - ergonomia) prevê, a partir da Análise Ergonômica do Trabalho (AET), a obrigatoriedade de pausas para descanso nas atividades que exijam sobrecarga muscular estática ou dinâmica do pescoço, ombros, dorso e membros superiores e inferiores (NR 17, item 17.6.3) (BRASIL, 1978b).

Um parâmetro importante para definir a repetitividade é o tamanho do ciclo medido em segundos. Entende-se por ciclo de trabalho a duração entre o início da operação e a mesma operação que será realizada na sequência. No caso do corte manual da cana-de-açúcar, o ciclo de trabalho inclui as operações de abraçar a cana, cortar com o uso de um facão (podão), jogar a cana até o centro do eito, formando a leira, e voltar à posição

6 O calculo da carga cardiovascular (CCV) está mais bem definido no item Materiais e Métodos. 
inicial para prosseguir o corte (LAAT et al., 2008). Conforme consagrado na literatura científica, ciclos menores que 30 segundos, durante mais de $50 \%$ da jornada de trabalho, representam riscos de lesões osteoarticulares (ASSUNÇÃO; VILELA, 2009).

Além dos indicadores de desgaste anteriormente mencionados, pode-se utilizar também a avaliação nutricional, como no estudo longitudinal de Luz et al. (2012), que se baseou na mesma amostra que compõe o presente estudo, cujos achados revelaram marcadores sanguíneos sugestivos de inflamação crônica e sistêmica expressados em perda de peso corporal na maior parte dos cortadores de cana acompanhados.

\section{Demanda, contexto e objetivo do estudo}

A investigação foi motivada, por um lado, pela constatação de elevados índices de acidentes de trabalho, monitorados a partir do Banco de Dados do Centro de Referência em Saúde do Trabalhador de Piracicaba (CEREST- Piracicaba), onde o setor agrícola se destacava dos demais segmentos econômicos formais do município pela alta incidência de acidentes de trabalho (ALMEIDA et al., 2012). Por outro lado, registrou-se no Estado de São Paulo a ocorrência de mortes de trabalhadores jovens nos canaviais, sem definição precisa de causalidade. O setor canavieiro era ainda motivo de várias ações de vigilância e de fiscalizações decorrentes de denúncias de precarização dos alojamentos de trabalhadores rurais, ensejando, na ocasião, a mobilização de várias instituições públicas da região reunidas no Fórum Trabalho e Cidadania para ações de vigilância e para maior compreensão do processo de trabalho e do desgaste da saúde dessa população (BRAGANTINI et al., 2009; MINAYO-GOMEZ, 2011; VILELA; MACHADO, 2011). O contexto da investigação, quando se considera a ocorrência das mortes por exaustão e a elevada taxa de acidentes no corte manual da cana, sugere a hipótese de que essa população de cortadores manuais, tendo em vista as exigências de performance para a permanência no emprego e a estimulação gerada pelo pagamento por produção, associados às altas temperaturas brasileiras durante a safra, aproxima-se perigosamente de situação de fadiga ou de estresse em níveis extremos, que, segundo Powers e Howley (2005), são estados clínicos causados por um conjunto de desordens fisiológicas em atividades prolongadas, incluindo desidratação, aumento da temperatura corporal e falta de substrato energético (carboidratos) para a atividade física exercida.

Este artigo tem como objetivo compreender, no trabalho dos cortadores de cana-de-açúcar, os determinantes organizacionais que intensificam a carga de trabalho e afetam a saúde dos trabalhadores. Espera-se que a demonstração da interação sistêmica de variáveis fisiológicas, ambientais e organizacionais possa fundamentar e fomentar o monitoramento, a vigilância e a melhoria das condições de trabalho e de saúde dessa população.

Esta pesquisa inseriu-se na perspectiva de resposta aos anseios dessa demanda pública e social.

A negociação para a pesquisa com uma grande usina da Região de Piracicaba decorreu no período de um ano, mas foi desautorizada pela empresa às vésperas do início da investigação no início da safra de 2007. O trabalho só pôde ser viabilizado pelo apoio interinstitucional do CEREST-Piracicaba, do de Campinas e pela intervenção da Gerencia Regional do MTE de Piracicaba, por meio de uma empreiteira de mão de obra, sob intervenção do MTE, que concordou com o estudo. Entretanto, no primeiro dia do trabalho de campo, os pesquisadores foram pressionados pela presença ostensiva de viaturas da usina, com o objetivo de amedrontar os trabalhadores, induzindo-os a não participar da pesquisa. Novamente a articulação interinstitucional por meio do MPT foi fundamental para assegurar o prosseguimento da investigação.

\section{Métodos}

Diante das dificuldades de acesso e da necessidade de análise em profundidade da atividade, optou-se por escolher por conveniência uma das 36 turmas contratadas por empreiteira rural auditada pelo MTE. A escolha da turma seguiu orientação do proprietário da empreiteira, que considerava essa turma como sendo uma das melhores em atividade na safra de 2007. Cada turma era composta por 40 trabalhadores. Esta foi a amostra inicial de participantes monitorados em três momentos durante a safra.

A turma escolhida era composta por migrantes vindos do Estado do Ceará, com jornada de trabalho de cinco dias corridos por um dia de descanso. Durante o desenvolvimento da pesquisa, houve perda de dez trabalhadores devido à demissão voluntária deles, antes do término da safra, e retorno às suas cidades de origem. As desistências foram explicadas pelos colegas de trabalho, principalmente por cansaço físico exacerbado, uma expressão do desgaste devido ao exercício de uma atividade muito exaustiva.

Aspectos clínicos dos trabalhadores, como hipertensão, diabetes, hipercolesterolemia, câncer, ansiedade/depressão não foram relatados pelo Serviço de Saúde Ocupacional da empresa estudada e tampouco relatado pelo grupo de trabalhadores. De modo análogo, os sujeitos também não declararam ser usuários de tabaco ou de outros tipos de drogas.

O estudo integrou o projeto "Ações interinstitucionais para o diagnóstico e prevenção de acidentes do 
trabalho: aprimoramento de uma proposta para a Região de Piracicaba”, financiado pela Fundação de Amparo a Pesquisa do Estado de São Paulo (FAPESP) sob n ${ }^{\circ}$ 06/51684-3.

Todos os trabalhadores assinaram o Termo de Consentimento Livre e Esclarecido e o projeto foi aprovado pelo Comitê de Ética em Pesquisa da Universidade Metodista de Piracicaba (UNIMEP), Protocolo $\mathrm{n}^{\mathrm{O}}$ 12/08.

\section{A estratégia adotada para compreender o trabalho e os riscos}

A ergonomia da atividade se debruça sobre os aspectos fisiológicos, buscando superar a abordagem das disciplinas clássicas, como a medicina do trabalho e a higiene ocupacional de tipo fatorial, que estudam fatores de risco e os respectivos efeitos de forma isolada (ASSUNÇÃO; LIMA, 2003). Essa abordagem da ergonomia tenta entender a relação desses vários aspectos em vista de uma compreensão global da atividade em seu contexto macro e micro, com um olhar a partir do trabalho real. Em outras palavras, interessa saber como a organização do trabalho determina e influencia a exposição, impondo uma carga, entendida enquanto custo humano global (mental, físico e cognitivo) do trabalhador; e, diante dessa determinação, como o trabalhador desenvolve sua atividade, como ele age, quais estratégias, regulações, quais margens de atuação são possíveis de adotar para dar conta das exigências impostas pela organização (WISNER, 1987; ASSUNÇÃO; LIMA, 2003; GUÉRIN et al., 2004).

Portanto, para entender a atividade do corte manual da cana-de-açúcar, utilizou-se o marco teórico-metodológico da Análise Ergonômica do Trabalho - AET (GUÉRIN et al., 2004). A AET é um método que possibilita a aquisição de conhecimentos sobre o funcionamento do ser humano em situação concreta de trabalho, tornando possível compreender seus determinantes (ASSUNÇÃO; LIMA, 2003). Na etapa preliminar, foram realizadas observações abertas do processo de trabalho, coletadas verbalizações dos trabalhadores, realizadas análises de documentos da empresa, que possibilitaram elaborar um pré-diagnóstico e nortear as observações sistemáticas na fase seguinte.

A observação sistemática da atividade foi realizada com especial atenção para monitorar os movimentos corporais, a frequência e a duração dos ciclos de corte, a frequência e a duração das pausas de descanso, o monitoramento da frequência cardíaca, o monitoramento da sobrecarga térmica e a produção diária dos sujeitos.

O processamento das variáveis foi realizado por meio da utilização do software CAPTIV L3000 (LAAT, 2010), o qual permite que estas possam ser integradas e quantificadas no tempo, em conjunto com a variável fisiológica da frequência cardíaca e as relacionadas com a carga térmica e com outras variáveis ambientais. O software possibilita a análise simultânea e integrada no tempo de vários parâmetros colhidos do vídeo, o qual registra os modos operatórios de interesse do pesquisador (movimento, postura, gestos, deslocamento, direção do olhar etc.) com outras variáveis fisiológicas ou ambientais.

\section{Observação da atividade}

Foram obtidas imagens, por meio de filmagens, das atividades de produção, com a utilização de câmera digital, cujos vídeos foram, posteriormente, codificados em variáveis de interesse relacionadas à atividade de trabalho, decompostas em: variáveis de operação - preparar, corte de três ruas, corte de uma rua, desponte da cana e pausa; variáveis de ação pegar lima, guardar lima, afiar facão, guardar água, retirar luva, carregar botija, pegar marmita, carregar marmita, abraçar o feixe de cana, cortar, segurar o feixe cortado, carregar e jogar, cortar a palha da cana deitada, ajuntar com a mão, ajuntar com o pé, jogar com a mão e jogar com o pé (chutar para fora da leira), beber, comer e outros; variáveis de postura - flexão e rotação de coluna lombar, posição em pé e posição sentado; variáveis de deslocamento - parado realizando o corte, parado tracionando os feixes, andando pelo menos com três passos e movimentos alternados de lateralidade direita e esquerda do tronco com até dois passos.

\section{Monitoramento da frequência cardíaca}

Para mensurar a frequência cardíaca dos trabalhadores, foram utilizados dez frequencímetros da marca Polar Modelo Team System ${ }^{\circledR}$ fixados em dez trabalhadores por dia, durante quatro dias, em três períodos diferentes - junho (quatro dias), setembro (quatro dias) e novembro (três dias) -, de modo a cobrir a totalidade da turma dos trabalhadores selecionada para acompanhamento. Uma das referências de análise foi a diferença entre a FCM de trabalho durante a jornada e a FCR, que tem sido adotada como um dos limites de tolerância para uma atividade de trabalho contínua para trabalhadores do gênero masculino (KROEMER; GRANDJEAN, 2005; LAAT et al., 2008). Para a medição, foram fixados os frequencímetros no peitoral dos trabalhadores, quando estes ainda se encontravam sentados no ônibus que os transporta para a lavoura, sendo que, após 5 minutos, o aparelho registrava a frequência basal (ou de repouso) de cada sujeito da pesquisa. 
Os valores de frequência cardíaca foram armazenados em intervalos de 5 segundos durante toda a jornada de trabalho e, ao final, descarregados em computador por meio de uma interface para compilação e para análise dos resultados.

Para a obtenção da CCV e para a análise dos resultados, utilizou-se a fórmula 1 proposta por Apud et al. (1989):

$$
C C V(\%)=\frac{(F C M-F C R)}{F C M a x t-F C R} \times 100
$$

FCM é a frequência cardíaca média durante a jornada de trabalho; FCR é a frequência cardíaca de repouso; FC Maxt é a frequência cardíaca máxima teórica estimada pela fórmula (220 menos idade).

\section{Monitoramento de variáveis ambientais e da carga térmica}

Para avaliação da carga térmica, foi utilizado o IBUTG, obtido por meio de instrumento digital modelo TGD 300 Digital, posicionado em área exposta ao sol, regulado na altura de 1,40 metro, correspondente à posição do tronco dos trabalhadores, durante a maior parte da jornada. Os dados do IBUTG foram registrados no próprio aparelho, a cada 10 segundos, com posterior descarregamento no computador. Além da sobrecarga térmica, foram monitoradas a temperatura ambiental e a umidade relativa do ar por meio da Estação Meteorológica Digital ITWMR-1075 da Faculdade de Saúde Pública da Universidade de São Paulo (USP).

\section{Monitoramento da produção diária}

Para a obtenção dos dados de produção diária de cada trabalhador, foram utilizadas as planilhas da empresa cujos valores foram calculados a partir da medição linear da cana cortada, convertida em peso por meio de estimativa de $\mathrm{kg} /$ metro, em cada talhão de corte.

\section{Análise de regressão}

Tendo em vista a hipótese inicial de que havia uma associação entre o aumento da CCV e as exigências de produtividade do trabalho, utilizou-se a análise estatística (modelo de regressão linear).

O modelo ajustado foi devidamente avaliado quanto à qualidade do ajuste e às pressuposições teóricas exigidas para sua adequação. Com base no teste de Shapiro-Wilk, os resíduos de todo o modelo ajustado seguiram distribuição normal, e uma análise gráfica dos resíduos versus dos valores preditos não revelou padrões fora da aleatoriedade.

\section{Resultados}

\section{"Maratonistas" do eito: mecanismos gerenciais para atingir as metas de produção}

Os trabalhadores sujeitos da pesquisa, todos migrantes do sexo masculino, ficavam alojados em casas alugadas pelo empregador, as quais contavam em média com oito a dez pessoas por casa. Recebiam marmitas de fornecedores contratados pela empresa, que lhes garantia almoço e jantar, sendo as demais refeições de responsabilidade de cada trabalhador. Entretanto, tanto as despesas de aluguel dos alojamentos quanto às referentes à alimentação dos trabalhadores eram descontadas mensalmente dos salários. Os contratos de trabalho eram formalizados apenas após o período de experiência de três meses de trabalho, período em que já ocorrem baixas na equipe, especialmente daqueles que participam pela primeira vez da atividade.

O trabalho de corte de cana é percebido pelos trabalhadores como uma atividade extremamente pesada, exaustiva, que leva ao desgaste funcional precoce, o que resulta na desistência de alguns antes do término da safra:

Quem trabalha com cana fica uns dez anos mais
velho, cada safra, pode por aí, uns três anos a mais gasto na vida.

\section{Ninguém quer cortar cana, não tem nenhum paulista, só nordestino, porque o trabalho é pesado. \\ O pessoal não aguenta, vai embora antes de setembro, o pagamento é pouco, o serviço é puxado e o risco de se machucar é grande.}

O contato inicial na negociação com os gestores da usina mostrou que o trabalho exaustivo é reconhecido pela gerência de produção agrícola, a qual, em contato com a equipe, assegurou que a produção no corte da cana: é baixa no início da safra devido ao processo de aquecimento e de adaptação dos trabalhadores; atinge o seu máximo no seu meio - junho e julho -, meses de temperaturas mais amenas, nas quais os trabalhadores já se adaptaram à rotina do trabalho; entra em declínio no final da safra devido ao cansaço dos cortadores, período em que ocorrem várias desistências voluntárias de trabalhadores.

Para compensar essas baixas, as chefias das usinas cobram metas, pressionam os trabalhadores para alcançá-las, utilizando-se de recursos gerenciais não preconizados nos manuais de administração, cujo objetivo é manter altos os índices de produtividade, como mostra a fala abaixo: 
Eu trabalhei em uma usina que o pessoal colocou um cortador bom de corte, que não faz parte da turma. Ele vem e fica forçando a gente a cortar mais, debocha e quer fazer competição. Ficou uma semana com a gente, ele era bom de corte.

Essa estratégia gerencial encontra similaridade com a contratação do "coelho" das maratonas esportivas, um atleta remunerado usado para acelerar o ritmo da corrida até uma determinada quilometragem e diminuir o tempo dos outros atletas na prova (LAAT, 2010).

Outra medida organizacional encontrada neste estudo, para acelerar o trabalho e manter a produtividade, foi a designação, pelas chefias, de dois trabalhadores para cortar nas mesmas ruas e em direção oposta, estabelecendo uma disputa entre eles:

Se eu não for mais longe com estas cinco ruas, eu não consigo cortar mais cana no dia, pois tem outro trabalhador vindo na minha direção e ele vem trazendo três ruas, aí eu não ganho a minha diária.

Por meio desses mecanismos de disputa no espaço do eito, a gestão do trabalho predetermina um "quantum" que deve ser alcançado por cada cortador, estimulando um ritmo acelerado de trabalho e eliminando as pausas, para que o trabalhador possa cortar "cada vez mais longe", disputando com aquele que vem na direção oposta. A produção menor significa a perda de uma diária compensadora, uma vez que a remuneração é baixa. Trata-se, portanto, de uma "maratona" iniciada pela disputa do território com os colegas de trabalho, mas que se realiza na disputa consigo mesmo, para in até o limite que o corpo possa aguentar.

Percebe-se, entretanto, que os trabalhadores utilizam de estratégias de regulação, acelerando o seu ritmo de trabalho na parte da manhã, até por volta de 10h30 (aproximadamente 4horas de trabalho), cortando três das cinco ruas estabelecidas para o eito, aproveitando-se da condição climática da temperatura mais amena e do seu potencial energético.

Nos dias muito quentes, em que as normas nacionais e internacionais recomendam medidas de controle de ampliação das pausas de descanso, as medidas autoritárias da gestão pelo aumento da produção vão em direção oposta, ocorrendo punições como a perda da "folga". A "folga" é o descanso remunerado, no valor, à época, de $\mathrm{R} \$ 15,00$, que o trabalhador recebia a cada cinco dias trabalhados. Quando os fiscais percebem que o trabalhador diminui a produção por parar antes do final da jornada ou se recusa a trabalhar em condição ainda mais adversa, por exemplo, a cana recém-queimada, eles fazem ameaças e aplicam punições como as evidenciadas nos relatos que se seguem:

Ontem estava muito quente e eu cortei só até as 11h. Hoje o fiscal já avisou que perdi a folga. É uma exploração, já me tiraram um monte de folga.
Se não cortar cana queimada no mesmo dia, eles não gostam, quando a gente entra direto na cana, bate e vai tudo pro pulmão. Já entrei pra cortar com fogo do lado mesmo. Se não cortar, eles chantageiam, cortam a folga.

Em outro testemunho de trabalhador, há indícios significativos da presença de alterações fisiológicas relacionadas ao trabalho exaustivo, em ritmo acelerado, estimulado pelas estratégias gerenciais e pelo pagamento por produção, intensificando o desgaste:

\section{Nunca vi alguém morrer, mas vi com câimbra. Na quentura o cortador sofre muito. Vi ano passado um que quis ganhar mais toneladas no dia quente e aí sofreu, caiu no chão e passou mal. Sempre aparecem esses problemas por causa do dia e da vontade de ganhar mais.}

Além das estratégias punitivas, a gestão aplica também técnicas gerenciais motivacionais, como os sorteios, que são amplamente usados na fase de declínio da produção, no final da safra, quando os níveis de fadiga estão muito significativos, podendo comprometer os resultados de produção, período em que ocorre maior número de desistências voluntárias. Os sorteios de carros, motos, bicicletas, equipamentos sonoros etc., são estímulos eficientes, uma vez que concorrem aos prêmios apenas os trabalhadores que conseguem vencer a "maratona", ou seja, aqueles que cortaram a cana nas metas estipuladas pela gestão e que não tiveram faltas nos últimos meses da safra.

Durante este estudo, fotografou-se o cartaz afixado no ônibus da turma pesquisada: "Natal motorizado". O mesmo cartaz definia como critério de participação no sorteio não ultrapassar duas faltas no período entre novembro e o final da colheita.

Cartaz semelhante foi identificado por outros pesquisadores em usina da região de Ribeirão Preto/SP, anunciando o sorteio de vários prêmios, incluindo um carro, para os cortadores com média diária acima de 12,5 toneladas e que não apresentassem faltas no período de 20 de outubro até o ultimo dia da safra (SANTOS, 2011).

\section{Observação sistemática da atividade: caso trabalhador " $D$ "}

Como indicado na metodologia, o software Captiv possibilita uma leitura mais global da carga de trabalho, integrando no tempo os observáveis de comportamento com outras variáveis ambientais e fisiológicas que podem ser processadas estatisticamente. A tecnologia também possibilita verificar momentos críticos de interesse, por exemplo, em um determinado instante de interesse, o posicionamento do trabalhador, o que fazia e os valores instantâneos de determinados parâmetros, conforme ilustrado na Figura 1: às 16 h08 do dia 7 de outubro de 2009, o trabalhador "D" apresentou 


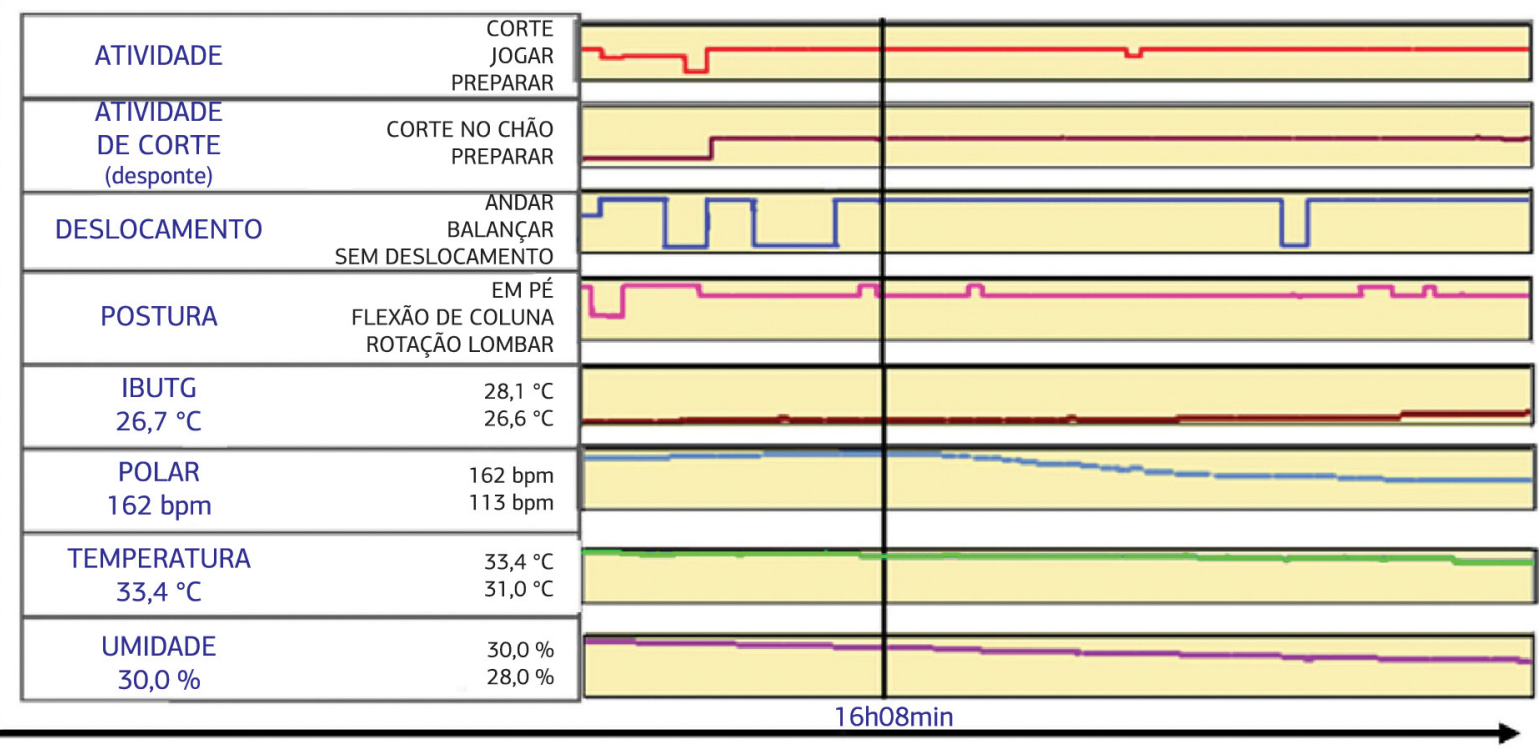

TEMPO

Figura 1 Resultado da análise integrada de variáveis de trabalho (ação executada, deslocamento, postura) na operação manual de corte de pontas de cana-de-açúcar com variáveis fisiológicas (frequência cardíaca) e ambientais (carga térmica, temperatura e umidade relativa), quantificadas ao longo do tempo para o trabalhador "D" e obtidas mediante uso do software CAPTIV L3000

frequência cardíaca de 162 bpm; nesse instante, está deslocando-se com flexão de coluna, com ciclo médio de trabalho repetitivo (6,73 segundos), realizando operação de corte das pontas (desponte). O IBUTG foi de $26,7^{\circ} \mathrm{C}$, acima do limite legal $\left(25^{\circ} \mathrm{C}\right)$; a temperatura ambiente foi de mais de $33^{\circ} \mathrm{C}$ e a umidade relativa foi baixa, em 30\%, indicando situação de elevada carga de trabalho e riscos múltiplos (LAAT, 2010).

De acordo com os dados obtidos por meio da codificação e do processamento dos filmes, foi possível ainda quantificar o número de ocorrências de cada variável selecionada. Por exemplo, obteve-se a informação que o trabalhador " $D$ " destinou durante o período de 107 minutos de filmagem 1.373 golpes de podão ${ }^{7}$ e realizou 1.209 flexões de coluna. Com base na medição linear de cana cortada durante o tempo da filmagem, a metragem total do dia e a produção do trabalhador amostrada pela empresa nesse dia, pode-se estimar que o trabalhador "D" realizou nesse dia cerca de 3.080 flexões de coluna e pelo menos 3.498 golpes de podão durante aproximadamente 8 horas de jornada de trabalho. Essa atividade, realizada em alta repetitividade, é composta por operações que exigem força, precisão no golpe, flexão de coluna
(44\% do tempo da atividade), atividade exercida em pé ( $43 \%$ do tempo), rotações de quadril ( $9 \%$ do tempo) e sentado ( $4 \%$ do tempo), as três primeiras em situações extremamente prejudiciais a saúde (LAAT, 2010). O golpe no feixe de cana é "devolvido" na forma de impactos no sistema musculoesquelético. Uma das evidências do risco de lesões é o tamanho do ciclo medido em segundos.

Do processamento estatístico, pode-se dimensionar o ciclo de trabalho no corte da cana, somando-se os tempos médios de cada ação que compõe a operação de corte em diversas modalidades. Com esse cálculo, obteve-se um ciclo médio no corte de três ruas de 5,68 segundos; no corte de uma rua, 4,36 segundos.

O software possibilitou ainda verificar o tempo de trabalho e o tempo de pausas que poderiam representar possibilidade de recuperação das estruturas musculoesqueléticas.

Quando analisamos o tempo dispensado na filmagem, o trabalho efetivo foi de $94 \%$, e apenas $6 \%$ do tempo foram usados para atividades como beber, comer e deslocar-se em micropausas, por exemplo, buscar a própria água e comida em outro local. O tamanho do ciclo e de sua permanência em 94\% do tempo de

\footnotetext{
7 A quantificação é conservadora, pois na codificação do filme não foi identificada cada golpe de podão, e sim a ação de golpear no tempo em que o trabalhador cortava a cana para concluir o ciclo unitário de cada feixe. Algumas situações podem exigir até três golpes de podão para concluir o corte de um feixe de cana.
} 
trabalho evidencia de modo inconteste o elevado risco de lesões osteoarticulares.

Outra evidência do custo do trabalho é a exigência de adoção da flexão de coluna para realizar a atividade. O caso “D” (Figura 1) realizava durante a filmagem o corte da cana "em pé", tipo de cana que facilita o "abrace" pelo trabalhador e exige menor quantidade de flexão da coluna em relação a outro tipo comum da cana, chamada de cana "em rolo", mais difícil de cortar. Para a cana "em pé”, observou-se que o trabalhador permaneceu $42 \%$ do tempo em pé, diferentemente da cana tipo "rolo", na qual se verificou, em outro momento, que o trabalhador ficou $62 \%$ do tempo em flexão da coluna (LAAT, 2010).

O corte da cana na posição dos feixes em pé, que predominou nos três períodos de observação, implica em redução do tempo da flexão da coluna, mas essa modalidade continua a representar risco ao sistema osteoarticular, como evidenciado no caso do trabalhador "D”, em que se constatou que ele permanece $43 \%$ do tempo total nessa posição. No caso “D”, observou-se ainda que as rotações de coluna, somando rotação ereta (5\%) com rotação e flexão lombar (4\%), chegam a 9\% do total do tempo de filmagem, índice elevado para essa postura, pois pode causar problemas na coluna vertebral.

\section{Observação sistemática e relação da frequência cardíaca, IBUTG e produção: caso trabalhador " $F$ "}

O monitoramento do trabalhador "F" evidenciou outra situação crítica, pois ele foi o que mais produziu na turma avaliada em setembro de 2007 e que alcançou patamares preocupantes: uma CCV de 57,4\% (Figura 2) e uma produção elevada de 22,4 toneladas no dia do monitoramento.

Observou-se ainda na Figura 2 que os pequenos picos de baixa na frequência cardíaca desse trabalhador corresponderam a escassas pausas, à exceção do período mais prolongado, de aproximadamente 45 minutos, que corresponde ao momento do deslocamento da turma no ônibus de uma fazenda para a outra, período em que sua frequência cardíaca alcançou seu limiar inferior da FCR. A frequência

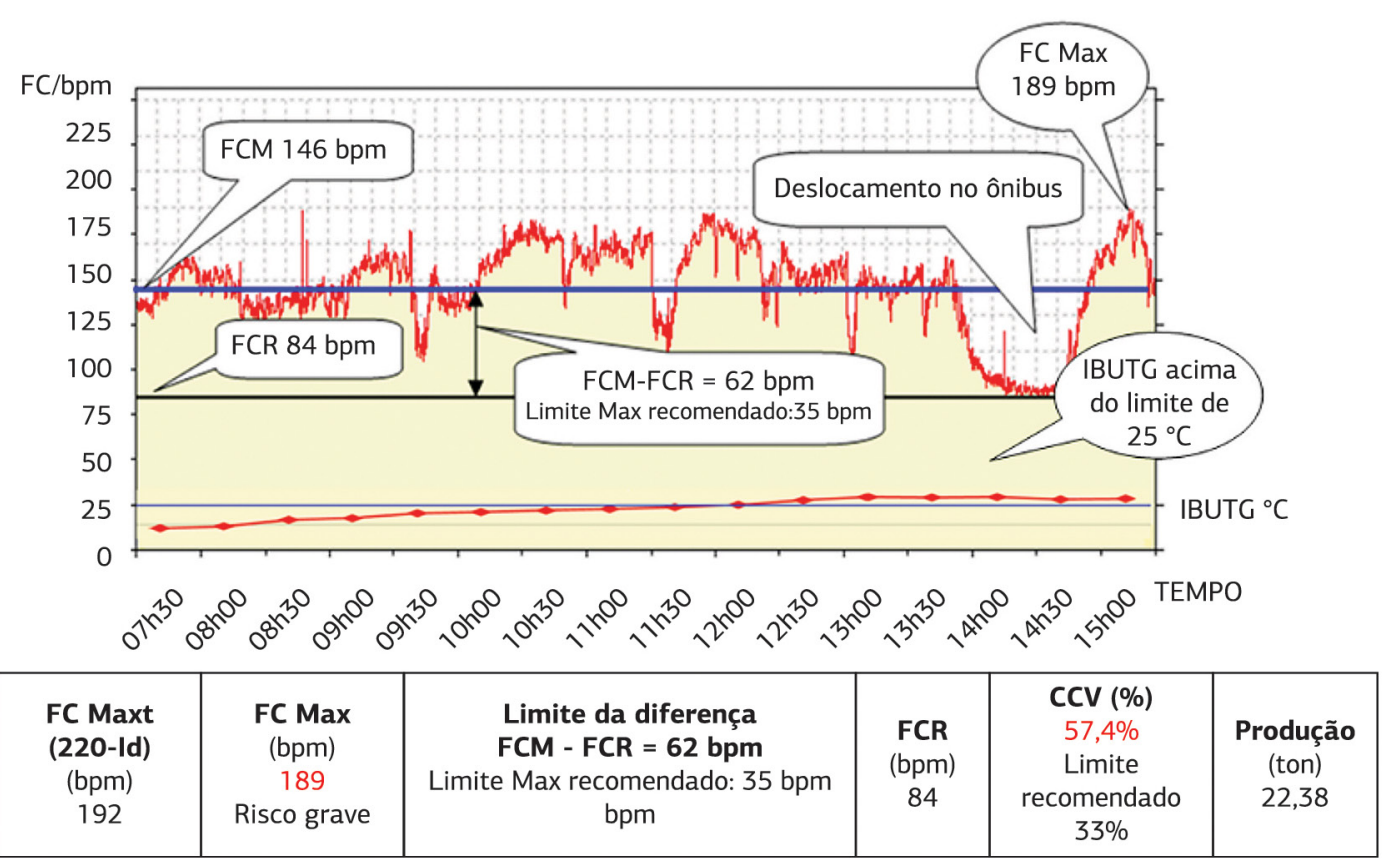

Figura 2 Monitoramento de parâmentros fisiológicos (frequência cardíaca) e do Índice de Bulbo Úmido Termômetro de Globo (IBUTG) durante uma jornada de trabalho no corte manual de cana-de-açúcar para o Trabalhador "F"

Limite do IBUTG: $25^{\circ} \mathrm{C}$

FCR: Frequência cardíaca de repouso, medida antes do início da atividade (bpm)

FC Maxt: Frequência cardíaca máxima teórica

FCM: Frequência cardíaca média durante a jornada (bpm)

FC Max: Frequência cardíaca máxima do sujeito, medida durante a jornada (bpm)

CCV: Carga cardiovascular

Limite da diferença: Quando a diferença da FCM menos a FCR ultrapassa 35 batimentos por minutos 
cardíaca máxima de 189 bpm foi alcançada quando o IBUTG, que foi aumentando durante o decorrer do dia, marcava $27,2^{\circ} \mathrm{C}$. Esse pico de batimento quase atingiu seu limite teórico de 192 bpm, estabelecido pela fórmula da frequência cardíaca máxima teórica (FCMaxt $=220$ menos a Idade). A situação pode ser avaliada como de risco grave, pois nenhuma atividade física deve ultrapassar esse limite teórico, com risco imediato de complicações à saúde, pois a frequência cardíaca máxima é o número máximo de batimentos que o coração pode atingir por minuto durante um determinado esforço (AMERICAN COLLEGE OF SPORTS MEDICINE, 2010).

Durante a jornada, a FCM desse trabalhador foi elevada, com 146 batimentos, ultrapassando o segundo limite de tolerância que é a diferença entre a FCM e a FCR, que alcançou no dia o valor de $62 \mathrm{bpm}$, sendo recomendada uma diferença de no máximo $35 \mathrm{bpm}$. A Figura 2 também mostra que o limite do IBUTG $\left(25^{\circ} \mathrm{C}\right)$ foi ultrapassado depois do meio-dia, assim mantido até o final da jornada, quando seria preconizada a adoção de 30 minutos de pausa em sombra para 30 minutos de trabalho, bem como outras medidas de controle não verificadas em nenhum momento da investigação.

\section{Monitoramento da frequência cardíaca e sua relação com a produção diária}

Quanto à frequência cardíaca, tomando-se por base a turma de 34 trabalhadores avaliados no mês de junho de 2007, observou-se que a população estudada alcançou uma produtividade média de 10,9 toneladas de cana cortada e os dados revelaram ainda que $82,4 \%$ dos trabalhadores estiveram acima do limite de 33\% da CCV. Os valores médios das três avaliações realizadas estão agregados na Tabela 1.

O mesmo padrão de resultados foi observado nos outros dois períodos avaliados, pois, em novembro, a média de produtividade foi de 7,6 toneladas para um grupo de 25 trabalhadores, com $56 \%$ dos trabalhadores acima do limite da CCV. Avaliando a média das diferenças entre as FCM e as FCR, observou-se a ultrapassagem do limite de 35 bpm nos três períodos de avaliação. Na análise da média de produção no mês de junho, $44,1 \%$ dos trabalhadores avaliados ficaram acima da média; em setembro e em novembro, 38,9\% e 40\%, respectivamente, ficaram acima.

Referindo-se ao mês de setembro, a Tabela 2 apresenta a magnitude de alguns resultados obtidos. A média de produtividade foi de 12,77 toneladas para um grupo de 36 trabalhadores; apenas nove não ultrapassaram esse limite. Em 20 dos outros 27 trabalhadores, encontrou-se a CCV acima do limite, como o caso do trabalhador "20", que corresponde ao caso "F" já explorado no item 3.2 anterior, cujo CCV alcançou valor de $57,40 \%$, com uma produção extremamente elevada de 22,38 toneladas. Esse trabalhador foi o que mais produziu no grupo, bem acima da média da turma, que foi de 12,77 toneladas.

Com relação ao parâmetro da diferença de 35 batimentos entre a FCM de trabalho e a FCR, com exceção do trabalhador " 36 ", que apresentou 26 batimentos de diferença, todos os demais extrapolaram o limite.

A média da CCV do grupo foi de $38,45 \%$, aproximadamente $17 \%$ acima do limite de $33 \%$. A diferença entre os batimentos da FCM durante o trabalho e a FCR no grupo foi de 51,52 batimentos médios, bem acima do prescrito de $35 \mathrm{bpm}$.

$\mathrm{O}$ ajuste por uma regressão linear simples entre a produção diária e a CCV está demonstrado na Tabela 3 e na Figura 3, em avaliação realizada considerando os três momentos de observação durante a safra, isto é, junho, setembro e novembro, em que se observa o efeito estatisticamente significativo entre o aumento da produtividade sobre a CCV.

Por meio da equação da reta obtida $Y(C C V)=28,324+0,8064 x$ (produção), pode-se estimar que, para cada aumento de 1 tonelada de cana na produção, implica no aumento de aproximadamente 0,81\% na CVV. Portanto, para exemplificar, uma produção de 15 toneladas implicaria na elevação estimada da CCV para o valor de 40,47\%. Esse achado

Tabela 1 Valores médios das idades, frequências cardíacas, carga cardiovascular, produção e limite da diferença FCM-FCR de trabalhadores na atividade de corte manual de cana-de-açúcar nos três períodos observados. Elias Fausto, SP, 2007

\begin{tabular}{cccccccccc}
\hline & & \multicolumn{9}{c}{ Média } \\
\cline { 3 - 9 } Mês da avaliação & $\begin{array}{c}\text { Número de trabalhadores } \\
\text { avaliados por período (N) }\end{array}$ & $\begin{array}{c}\text { Idade } \\
\text { (ano) }\end{array}$ & $\begin{array}{c}\text { FCMaxt } \\
(220 \text { menos } \\
\text { idade) }\end{array}$ & $\begin{array}{c}F C M \\
(b p m)\end{array}$ & $\begin{array}{c}F C R \\
(b p m)\end{array}$ & CCV(\%) & $\begin{array}{c}\text { Produção } \\
\text { (ton) }\end{array}$ & $\begin{array}{c}\text { FCM-FCR } \\
\text { (bpm) }\end{array}$ \\
\hline Junho & 34 & 26,9 & 193,4 & 108,3 & 56,4 & 35,7 & 10,9 & 51,9 \\
Setembro & 36 & 26,5 & 193,4 & 110,4 & 58,8 & 38,4 & 12,8 & 51,5 \\
Novembro & 25 & 26,7 & 193,3 & 104,6 & 59,5 & 33,7 & 7,6 & 45,0 \\
\hline
\end{tabular}


Tabela 2 Parâmetros fisiológicos, carga cardiovascular e produção dos trabalhadores na atividade de corte manual de cana-de-açúcar no mês de setembro de 2007. Elias Fausto, SP

\begin{tabular}{|c|c|c|c|c|c|c|c|}
\hline Cortadores & $\begin{array}{l}\text { Idade } \\
\text { (anos) }\end{array}$ & FCMaxt (bpm) & FCM (bpm) & FCR (bpm) & $C C V(\%)$ & $F C M-F C R$ & $\begin{array}{l}\text { Produção } \\
\text { (ton/dia) }\end{array}$ \\
\hline 1 & 21 & 199 & 109 & 59 & 35,71 & 50 & 11,61 \\
\hline 2 & 42 & 178 & 89 & 54 & 28,22 & 35 & 11,52 \\
\hline 3 & 21 & 199 & 119 & 59 & 42,85 & 60 & 13,50 \\
\hline 4 & 31 & 189 & 87 & 45 & 29,16 & 42 & 10,80 \\
\hline 5 & 24 & 196 & 101 & 53 & 33,56 & 48 & 11,70 \\
\hline 6 & 19 & 201 & 113 & 52 & 40,93 & 61 & 13,32 \\
\hline 7 & 22 & 198 & 106 & 49 & 38,25 & 57 & 17,85 \\
\hline 8 & 31 & 189 & 117 & 60 & 44,18 & 57 & 19,98 \\
\hline 9 & 23 & 197 & 105 & 63 & 31,34 & 42 & 9,69 \\
\hline 10 & 25 & 195 & 100 & 51 & 34,02 & 49 & 12,67 \\
\hline 11 & 27 & 193 & 127 & 57 & 51,47 & 70 & 10,14 \\
\hline 12 & 18 & 202 & 100 & 55 & 30,61 & 45 & 6,94 \\
\hline 13 & 22 & 198 & 107 & 52 & 37,67 & 55 & 8,01 \\
\hline 14 & 30 & 190 & 100 & 59 & 31,29 & 41 & 8,40 \\
\hline 15 & 28 & 192 & 99 & 56 & 31,61 & 43 & 7,35 \\
\hline 16 & 42 & 178 & 97 & 57 & 33,05 & 40 & 11,52 \\
\hline 17 & 25 & 195 & 126 & 67 & 46,09 & 59 & 6,84 \\
\hline 18 & 21 & 199 & 98 & 57 & 28,87 & 41 & 5,94 \\
\hline 19 & 20 & 200 & 119 & 69 & 38,16 & 50 & 11,07 \\
\hline $20^{*}$ & 28 & 192 & 146 & 84 & $\mathbf{5 7 , 4 0}$ & 62 & 22,38 \\
\hline 21 & 30 & 190 & 117 & 55 & 45,92 & 62 & 8,10 \\
\hline 22 & 19 & 201 & 119 & 68 & 38,34 & 51 & 19,65 \\
\hline 23 & 19 & 201 & 118 & 59 & 41,54 & 59 & 15,68 \\
\hline 24 & 31 & 189 & 90 & 54 & 26,66 & 36 & 9,88 \\
\hline 25 & 26 & 194 & 110 & 59 & 37,77 & 51 & 19,18 \\
\hline 26 & 36 & 184 & 115 & 53 & 47,32 & 62 & 15,67 \\
\hline 27 & 24 & 196 & 115 & 70 & 35,71 & 45 & 11,07 \\
\hline 28 & 22 & 198 & 105 & 57 & 34,04 & 48 & 11,38 \\
\hline 29 & 32 & 188 & 127 & 68 & 49,16 & 59 & 20,43 \\
\hline 30 & 25 & 195 & 107 & 51 & $\mathbf{3 8 , 8 8}$ & 56 & 19,03 \\
\hline 31 & 34 & 186 & 120 & 60 & 47,61 & 60 & 13,14 \\
\hline 32 & 21 & 199 & 123 & 48 & 49,66 & 75 & 10,20 \\
\hline 33 & 36 & 184 & 128 & 78 & 47,16 & 50 & 14,04 \\
\hline 34 & 39 & 181 & 105 & 48 & 42,85 & 57 & 12,42 \\
\hline 35 & 18 & 202 & 112 & 61 & 36,17 & 51 & 19,98 \\
\hline 36 & 25 & 195 & 97 & 71 & 20,96 & 26 & 8,88 \\
\hline Média & 26,58 & 193,41 & 110,36 & 58,83 & 38,45 & 51,52 & 12,77 \\
\hline
\end{tabular}

FC Maxt: Frequência cardíaca máxima teórica estimada pela fórmula (220 menos idade)

FCM: Frequência cardíaca média durante a jornada de trabalho

FCR: Frequência cardíaca de repouso

CCV: Carga cardiovascular em \%

FCM-FCR: Diferença entre frequência cardíaca de repouso e frequência cardíaca média

*Trabalhador "F" cujos parâmetros fisiológicos estão explorados na Figura 2

Obs.: Dados em negrito ultrapassam o limite de CCV 
mostra a contribuição específica do aumento da produção sobre o aumento do desgaste cardíaco, ou seja, quanto maior a cobrança, os estímulos e as pressões por aumento da produtividade, maior o risco à saúde desses trabalhadores.

A Figura 3 exibe a relação entre a produção e a CCV, bem como o intervalo de confiança dos dados considerando os três períodos de análise.

A magnitude do modelo de ajuste da produção encontrada mostra o quanto as toneladas de cana colhidas estão associadas às alterações na frequência cardíaca.

Em suma, na análise de parâmetros fisiológicos objetivos, esta pesquisa demonstrou que os trabalhadores estão expostos a uma complexidade de fatores interativos, como trabalho exaustivo, o estresse por calor e metas para cumprir sua produção.
O modelo de regressão linear (Tabela 3 e Figura 3) considerou apenas como variável de exposição a produção em toneladas a fim de testar a hipótese de que o CCV estava associado a essa exposição. Desconsiderou-se a possibilidade de introduzir no modelo variáveis que pudessem atuar como confundidoras dessa associação, pois o grupo estudado apresentou uma homogeneidade considerável quanto ao sexo, idade, local de procedência, empresa contratante, tipo de jornada de trabalho e estado de saúde.

Apesar de o $\mathrm{R}^{2}$ (Tabela 3) indicar que o trabalho exaustivo, medido pela variável produção em toneladas, explica apenas 1/4 do CCV, as demais observações feitas dos parâmetros fisiológicos, como o estresse por calor e as metas para cumprir a produção, permitem considerar que os trabalhadores estão expostos a uma complexidade de fatores interativos, que inclui a contribuição expressiva da variável produção.

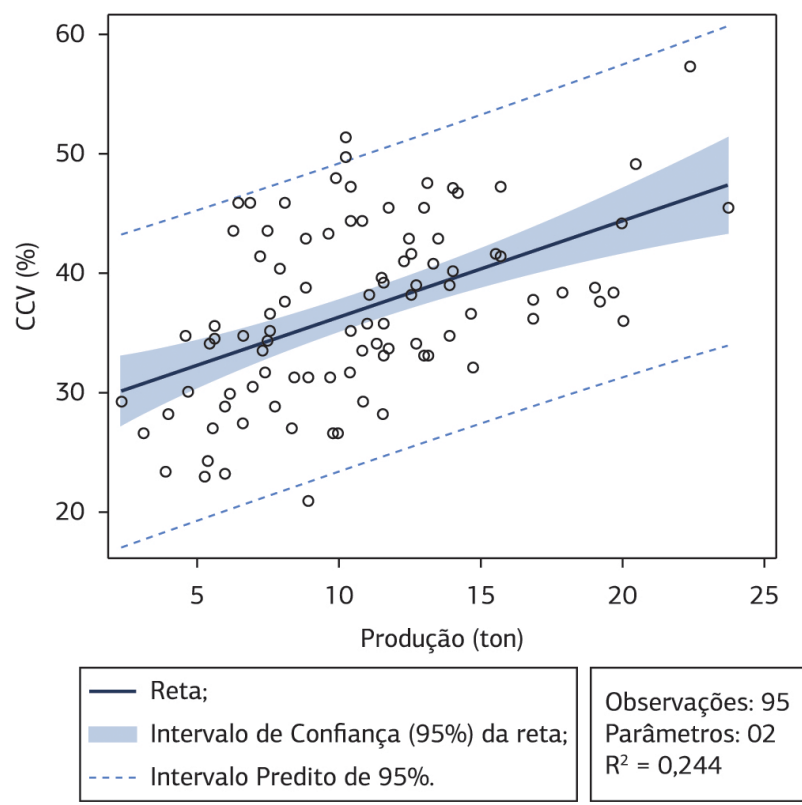

Figura 3 Relação entre a carga cardiovascular (em \%) e a produção (em toneladas) dos cortadores de cana-de-açúcar nos três períodos estudados (junho, setembro e novembro de 2007)

Tabela 3 Modelo de regressão linear ajustado para explicar a carga cardiovascular em função da produção, em toneladas, no corte manual de cana-de-açúcar em três períodos de avaliação ( $\left.{ }^{*}\right)$

\begin{tabular}{|c|c|c|c|c|}
\hline Momento & & Estimativa de $\beta$ & $p$ & $I C(\beta)_{95 \%}$ \\
\hline \multirow{3}{*}{$\begin{array}{l}\text { Avaliação global nos três } \\
\text { períodos }(n=95)\end{array}$} & Constante & 28,3 & $<0,0001$ & $(24,9-31,7)$ \\
\hline & Produção (ton) & 0,8 & $<0,0001$ & $(0,5-1,1)$ \\
\hline & \multicolumn{4}{|c|}{ Qualidade do ajuste: $F=30,0 ; p<0,0001 ; R^{2}=0,244$} \\
\hline
\end{tabular}

*Junho, setembro e novembro de 2007 


\section{Discussão}

Os impactos do trabalho em ritmo acelerado e puxado pelas cobranças de produção são agravados por hidratação e alimentação inadequadas, conforme apurado por Luz et al. (2014), que realizaram a avaliação nutricional da mesma turma estudada e constataram que os trabalhadores ingeriam de 5 a 10 litros de água/dia e que a diluição dos repositores eletrolíticos foi inferior à adequada. A alimentação durante a safra não garantia a segurança alimentar e nutricional. A alimentação foi monótona (com pouca variação e se repetiu ao longo das semanas de observação), conservada e consumida em temperatura inadequada, e incompatível com os hábitos culturais dos trabalhadores, gerando desperdício e redução do consumo alimentar.

A contribuição da análise ergonômica permitiu elucidar aspectos importantes da situação de trabalho e como o processo e as relações de trabalho impactam na atividade ou no trabalho real ${ }^{8}$.

Os resultados aqui apresentados demonstram que a produtividade do corte manual da cana depende exclusivamente do ritmo e da frequência do desempenho humano no manuseio do podão, uma vez que não houve inovação tecnológica nem dos instrumentos, nem do processo de trabalho (ALVES, 2008; NOVAES, 2007; RAMOS, 2007).

No entanto, a produtividade aumentou no setor, dobrando nos últimos 20 anos, por meio de técnicas gerenciais de seleção dos mais resistentes, baseadas em critérios de habilidade, destreza, força e resistência física, métodos autoritários de gestão que aceleram o trabalho e garantem as metas de produção e as estratégias de motivação como bônus e prêmios. Segundo Novaes (2007, p. 171), “[...] a força física e a destreza são critérios imprescindíveis para assegurar o aumento da produtividade nesse sistema de corte que supõe a intensificação do ritmo de trabalho."

A medição e a análise das variáveis fisiológicas diagnosticaram a penosidade do trabalho desenvolvido nos canaviais, que aparece nas posturas forçadas e nos movimentos repetitivos dos trabalhadores, que podem levar a comprometimentos importantes na saúde do sistema musculoesquelético, bem como a elevada CCV associada às altas temperaturas, à umidade baixa, ao ritmo de trabalho acelerado e sem pausas, à quantidade de cana cortada; portanto, ao esforço físico despendido, tornando o trabalho também perigoso pela magnitude do risco.

A análise ergonômica, por sua vez, detectou questões organizacionais relacionadas ao sistema de pagamento por produção, o qual impõe aos trabalhadores uma pressão invisível que pode ser comparada a uma maratona esportiva, porém em condições atmosféricas adversas, sem preparo ou orientação, sem alimentação adequada e sem períodos necessários de descanso e de recuperação muscular.

Oliveira (2007) relatou que o pagamento por produção aos trabalhadores do corte de cana, implantado no Brasil a partir de 1986, trouxe aumento nas exigências de esforço físico nesse tipo de trabalho, levando-os a superar, muitas vezes, as suas capacidades de trabalho.

Alves (2006) constatou que, entre 1986 e 2006, a produtividade do trabalho dos cortadores de cana dobrou de 6 toneladas de cana/homem/dia para 12 toneladas cana/homem/dia.

O presente estudo, assim como os demais citados, desvelou ainda que, sob o estímulo financeiro de aumento dos seus ganhos diários e de garantia de permanência na próxima safra, os trabalhadores tendem a ultrapassar seus limites fisiológicos. Desprovidos das estratégias de autorregulação, submetidos ao mando autoritário e ao medo de punições, os trabalhadores que resistem ao processo desgastante lutam contra os sinais de cansaço e de desconforto, mantendo-se na corrida pela sobrevivência, o que justifica o uso do conceito da "maratona" perigosa no corte manual da cana-de-açúcar.

Cabe destacar que o pagamento por produção adotado no setor contraria a legislação vigente, uma vez que a NR 17 (ergonomia) do MTE (BRASIL, 1978b) indica que, nas atividades que exijam sobrecarga muscular estática ou dinâmica do pescoço, ombros, dorso e membros superiores e inferiores, todo e qualquer sistema de avaliação de desempenho para efeito de remuneração e de vantagens de qualquer espécie deve levar em conta as repercussões sobre a saúde dos trabalhadores.

A "maratona" penosa e perigosa nos canaviais evidenciou-se de diferentes formas: (1) pelo trabalho intensificado, em ciclos de trabalho extremamente curtos (4 a 6 segundos); (2) pela ausência de pausas, presentes em apenas 6\% do tempo trabalhado; (3) pelas exigências de força, de precisão e de uso de posturas extremas, que ocuparam $94 \%$ do tempo total de trabalho; (4) pela ultrapassagem sistemática do limiar de risco cardiovascular; (5) pela extrapolação frequente do limite de sobrecarga térmica, sem a adoção de medidas de repouso em sombra, recomendadas pela legislação; (6) finalmente, pela associação perversa entre o aumento da produtividade estimulado pelo pagamento por produção e por outras estratégias

\footnotetext{
8 Mais detalhes sobre a tarefa prescrita como quantidade de ruas, sistema de marcação e de medição, controle da produção realizada e paga, as variabilidades encontradas na rotina de trabalho como cana em pé, cana de rolo ou cana deitada, variabilidades do terreno etc., podem ser encontradas em Laat (2010).
} 
gerenciais, como os sorteios aos "vencedores", e o aumento da sobrecarga cardiovascular, comprovada estatisticamente.

Enquanto um atleta profissional tem toda uma logística de apoio como preparo prévio, treinamento físico, alimentação balanceada, supervisão de preparador físico, entre outros profissionais, o cortador se vê diante de uma "maratona" perigosa, uma corrida solitária em busca de aumento para seu sustento, e vendo sua vida encurtar: "[...] a cada safra uns três anos a mais gastos na sua vida."

\section{Da saúde da cana para a saúde do trabalhador}

Diante dessas questões que colocam a saúde dos trabalhadores do corte de cana em risco, buscam-se iniciativas de políticas públicas que objetivam controlar, minimizar e banir os impactos nocivos dessas atividades.

No tocante à poluição gerada pela queimada e os seus impactos na saúde da população, foi promulgada no Estado de São Paulo a Lei ${ }^{0} 11.241$, que define o fim da queima da cana em áreas mecanizáveis até 2021 e em áreas não mecanizáveis até 2031 (SÃO PAULO, 2002). Em decorrência de evidências relacionando o impacto dessas queimadas nas emissões de poluentes e o aumento da mortalidade entre crianças e idosos (CANÇADO et al., 2006), e diante do prazo longo dado pela legislação estadual, em junho de 2007, o governo do Estado firmou com a UNICA um protocolo agroambiental, visando ao fim das queimadas até o ano de 2014 nas áreas mecanizáveis e 2017 nas áreas não mecanizáveis, com a adesão de 127 usinas e 23 associações de fornecedores de cana (SÃO PAULO, 2007).

Conforme descrevem Minayo-Gomez (2011), Bragantini et al. (2009) e Vilela e Machado (2011), foram desenvolvidas ações intersetoriais envolvendo o MPT da $15^{\text {a }}$ Região, MTE, CEREST(s) e Vigilâncias Sanitárias, com destaque para a Região de Piracicaba, que conseguiu reunir sindicatos e organizações da sociedade civil, as quais, aliadas às pesquisas acadêmicas, propiciaram condições favoráveis para o desenvolvimento de ações de vigilância com vistas a assegurar direitos, inibir as práticas de terceirização e propiciar condições mínimas de trabalho, moradia, alimentação, suprimento de água e outros aspectos igualmente relevantes para tornar essa atividade minimamente suportável para essa população.

No entanto, como forma de facilitar o acesso do etanol ao mercado internacional, o governo brasileiro, por meio do Gabinete da Casa Civil, articulou o denominado
"Compromisso Nacional para Aperfeiçoar as Condições de Trabalho na Cana-de-Açúcar”, apoiado por vários ministérios e por representações de trabalhadores (BRASIL, 2010a, 2011). Tal acordo tripartite teve como objetivo a certificação das usinas com vistas a implantar melhoria nas condições de trabalho; todavia, o sistema de certificação é privado, financiado pelas usinas, sem o controle público do processo. À exceção do fim das terceirizações, que representou um avanço nas relações de trabalho, especialmente, para outros Estados da federação, uma vez que em São Paulo essa prática já havia sido eliminada por conta da atuação pública, a lista de verificação para fins de auditoria contempla basicamente itens já previstos na legislação e outros anedóticos, como observância de ginástica laboral para os cortadores de cana!

Os resultados do presente estudo indicam a importância da eliminação do sistema de pagamento por produção, conforme apresentado em Oficina Nacional denominada "Da Saúde da Cana para a Saúde do Trabalhador" (BRASIL, 2010b), realizada em agosto de 2010, da qual participaram pesquisadores, representantes de federações e confederações de trabalhadores, dos órgãos públicos de vigilância como Ministério da Saúde, MTE e do MPT. No evento, não houve consenso entre os representantes sindicais quanto às mudanças na forma de remuneração dos trabalhadores rurais, sob a argumentação de que o fim do pagamento por produção poderia implicar em rebaixamento nos salários da categoria. Dessa forma, o banimento do pagamento por produção continua fora das negociações, a despeito das evidências científicas sobre os efeitos danosos dessa forma de remuneração na saúde dos trabalhadores, com impactos negativos tais como o sacrifício, a fadiga, a doença e, até mesmo, a morte, que contrariam a imagem de um etanol que se tenta vender como combustível "limpo e sustentável”, contradições que estão debatidas no vídeo documentário "Linha de Corte" (2013). Tendo em vista as evidências da relação entre o pagamento por produção e os riscos à saúde, a ações do MPT e do Ministério da Justiça, buscam limitar essa prática insustentável (BRASIL, 2012). Estudo de Rodrigues (2014) revelou que o pagamento por produção foi incorporado nas relações de trabalho no corte mecanizado de cana-de-açúcar e continua fazendo seus danos à saúde e à integridade das equipes nas frentes de trabalho mecanizado. A autora reanalisou cinco acidentes graves, sendo quatro fatais, que ocorreram com as máquinas colhedoras de cana, e descreveu como o pagamento por produção provoca a intensificação do trabalho, a correria e o "bate e volta" de homens e máquinas, em uma tentativa de tornar contínuo o fluxo de abastecimento das usinas,

\footnotetext{
9 Expressão usada pelos trabalhadores entrevistados pela autora para designar a natureza ininterrupta do corte mecanizado.
} 
incluindo o trabalho de corte mecanizado durante o período noturno. A análise do material joga por terra o discurso oficial de que os problemas do setor canavieiro seriam resolvidos com a mecanização da colheita:

Inovação tecnológica, quando herda o pagamento por produção e o conjunto dos mecanismos de pressão das relações de trabalho do processo manual, carrega no seu seio os riscos e perigos daquela modalidade. (VILELA et al., 2014, p. 4666-4667).

A "maratona” parece persistir, talvez agora mais veloz e mais perigosa, requisitando novas investigações científicas associadas a novas iniciativas de políticas públicas.

Uma limitação da avaliação fisiológica é a desistência de parte dos sujeitos no decorrer da investigação, o que significa que apenas os mais aptos física e psicologicamente se mantêm até o final, uma vez que vários trabalhadores deixaram a atividade antes do fim da safra por motivos diversos, como dores musculares, dificuldades físicas, distância da família, dívidas contraídas e troca por empregos menos desgastantes. Essa limitação sugere a necessidade de estudos epidemiológicos para monitorar efeitos de longo prazo na população de cortadores de cana.

Os resultados da investigação e a carência de um diagnóstico sobre o perfil de morbidade e de mortalidade desses trabalhadores sugerem a necessidade de vigilância e de novas pesquisas sobre a saúde e o possível envelhecimento precoce dessa categoria.

Outros estudos também são necessários para verificar a continuidade do pagamento por produção no corte mecanizado e os seus efeitos adversos à saúde do trabalhador.

\section{Contribuições de autoria}

Os autores contribuíram igualmente nas diversas fases da investigação e da redação do artigo, as quais incluíram coleta de dados, análise, redação, revisão e aprovação do texto para publicação.

\section{Agradecimentos}

À equipe do CEREST Piracicaba, à Gerencia do Ministério do Trabalho e Emprego e aos Procuradores do MPT da $15^{\text {a }}$ Região pelo apoio institucional. Ao Dr. Hélio Rubens Nunes e Kleber dos Santos, pelo auxílio nas análises estatísticas. À Fundação de Amparo à Pesquisa do Estado de São Paulo (FAPESP), processo nº 06/51684-3. À Coordenação de Aperfeiçoamento de Pessoal de Nível Superior (Capes), pela disponibilização de bolsas de pós-graduação a membros da equipe.

\section{Referências}

ALMEIDA, I. M. et al. Vigilância e Prevenção de Acidentes de Trabalho: Reflexões e práticas do SIVAT Piracicaba - SP. In: CORRÊA, M. J. M.; PINHEIRO, T. M. M.; MERLO, A. R. C. (Org.). Vigilância em Saúde do Trabalhador no Sistema Único de Saúde: teorias e práticas. Belo Horizonte: Coopmed, 2012. v. 1, p. 182-210.

ALVES, F. Políticas públicas compensatórias para a mecanização do corte de cana crua: indo direto ao ponto. Ruris, Campinas, v. 3, p. 145-165, 2009.

. Por que morrem os cortadores de cana? Saúde e Sociedade, São Paulo, v. 15, n. 3, p. 90-98, 2006. http://dx.doi.org/10.1590/S0104-12902006000300008.

Processo de trabalho e danos à saúde dos cortadores de cana. InterfacEHS, São Paulo, v. 3, n. 2, p. 1-26, 2008.

AMERICAN COLLEGE OF SPORTS MEDICINE ACSM. ACSM's guidelines for exercise testing and
prescription/ACSM. 6. ed. Philadelphia: Lippincott Williams \& Wilkins, 2010.

AMERICAN CONFERENCE OF GOVERNMENTAL INDUSTRIAL HYGIENISTS - ACGIH. Limites de Exposição Ocupacional (TLVs) para substâncias químicas e agentes físicos e Índices Biológicos de Exposição (BEI) 1999. Tradução de Associação Brasileira de Higienistas Ocupacionais - ABHO. São Paulo: ABHO, 1999.

ANDRADE, M. C. Modernização e pobreza: a expansão da agroindústria canavieira e seu impacto social e ecológico. São Paulo: Editora UNESP, 1994.

APUD, E. et al. Guide-lines on ergonomics study in forestry. Genebra: ILO, 1989.

APUD, E. Temas de ergonomia aplicados al aumento de la productividad de la mano de obra en cosecha florestal. In: SIMPÓSIO BRASILEIRO SOBRE COLHEITA E TRANSPORTE FLORESTAL, 3., 1997. Vitória. Anais... Vitória: SIF/DEF, 1997. p. 46-60. 
ASSUNÇÃO, A. A.; LIMA, F. A. P. A contribuição da ergonomia para a identificação, redução e eliminação da nocividade do trabalho. In: MENDES, R. (Org.). Patologia do trabalho. Rio de Janeiro: Atheneu, 2003. p. $1768-1789$.

ASSUNÇÃO, A. A.; VILELA, L. V. Lesões por esforços repetitivos: guia para profissionais de saúde. Piracicaba: Centro de Referência em Saúde do Trabalhador, 2009.

AZEVEDO, L. Histórico dos cortadores de cana mortos no setor canavieiro. Guariba: Pastoral do Migrante, 2007. Disponível em: < http://pastoraldomigrante.org. br/historico-dos-cortadores-de-cana-mortos-no-setorcanavieiro/>. Acesso em: 20 ago. 2014.

BACCARIN, J. G.; GEBARA, J. J.; BORGES JUNIOR, J. C. Expansão canavieira e ocupação formal em empresas sucroalcooleiras do Centro-Sul do Brasil, entre 2007 e 2009. Revista de Economia Sociologia Rural, Brasília, v. 49, n. 2, p. 495-507, 2011.

BERGERON, M. F. et al. Youth football: heat stress and injury risk. Medicine and Science in Sports and Exercise, Hagerstown, v. 37, n. 8, p. 1421-1430, 2005. http://dx.doi.org/10.1249/01. mss.0000174891.46893.82. PMid:16118592.

BITENCOURT, D. P.; RUAS, A. C.; MAIA, P. A. Análise da contribuição das variáveis meteorológicas no estresse térmico associada à morte de cortadores de cana-de-açúcar. Cadernos de Saúde Pública, Rio de Janeiro, v. 28, n. 1, p. 65-74, 2012. http://dx.doi. org/10.1590/S0102-311X2012000100007.

BRAGANTINI, C. A. et al. Fórum de Cidadania Justiça e Cultura de Paz: uma experiência de Vigilância em Saúde do Trabalhador Canavieiro na Região de Piracicaba - SP. In: EXPOEPI MOSTRA NACIONAL DE EXPERIÊNCIAS BEM-SUCEDIDAS EM EPIDEMIOLOGIA, PREVENÇÃO E CONTROLE DE DOENÇAS, 9., 2009, Brasília, DF. Anais... Brasília, DF: Ministério da Saúde, 2009. p. 16-20.

BRASIL. Ministério do Trabalho e Emprego. Portaria n. ${ }^{\circ}$ 3.214, de 08 de junho de 1978. Norma Regulamentadora NR 15: atividades e operações insalubres. Diário Oficial [da] República Federativa do Brasil. Brasília, DF, 6 jun. 1978a. Disponível em: <http://portal.mte.gov.br/legislacao/normaregulamentadora-n-15-1.htm $>$. Acesso em: 14 maio 2015.

. Ministério do Trabalho e Emprego. Portaria n. ${ }^{\circ} 3.214$, de 08 de junho de 1978. Norma Regulamentadora 17: Ergonomia. Diário Oficial [da] República Federativa do Brasil. Brasília, DF, 8 jun. 1978b. Disponível em: <http://portal.mte.gov.br/data/ files/FF8080812BE914E6012BEFBAD7064803/nr_17. pdf $>$. Acesso em: 14 maio 2015.

- Ministério da Previdência Social. Anuário estatístico da Previdência Social. Brasília, DF:
Ministério da Previdência Social, 2008. (Informe da Previdência Social, v. 20).

. Decreto de 24 de novembro de 2010. Cria a Comissão Nacional de Diálogo e Avaliação do Compromisso Nacional para Aperfeiçoar as Condições de Trabalho na Cana-de-Açúcar, e dá outras providências. Diário Oficial [da] República Federativa do Brasil. Brasília, DF, 25 nov. 2010a. Disponível em: $<$ http://www.planalto.gov.br/ccivil_03/_ato20072010/2010/Dnn/Dnn12937.htm >. Ácesso em: 14 maio 2015.

. Resolução da oficina da "Saúde da Cana" à saúde do trabalhador: como melhorar as condições de vida e trabalho no setor canavieiro. Piracicaba: Ministério da Saúde: Fiocruz, 2010b. Mimeo.

. Secretaria Geral da Presidência da República.

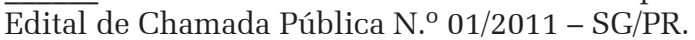
Estabelece condições de credenciamento de empresas de auditoria junto à Comissão Nacional de Diálogo e Avaliação de Compromisso Nacional para Aperfeiçoar as Condições de Trabalho na Cana-de-Açúcar. Diário Oficial [da] República Federativa do Brasil. Brasília, DF, 15 jul. 2011. Disponível em: <http:// www.secretariageral.gov.br/compromissos-nacionais/ canadeacucar/publicacoes-e-documentos/edital/ editalchamadapublica_cana.pdf $>$. Acesso em: 14 maio 2015.

. Ministério Público do Trabalho. Poder Judiciário Federal. Justiça do Trabalho $15^{\mathrm{a}}$ Região. Vara do Trabalho de Matão. Sentença. Matão, 24 out. 2012. Proc: 0001117-52.2011.5.15.0081.

CANÇADO, J. E. D. et al. The impact of sugar caneburning emissions on the respiratory system of children and the elderly. Environmental Health Perspectives, Research Triangle Park, v. 114, n. 5, p. 725-729, 2006. http://dx.doi.org/10.1289/ehp.8485. PMid:16675427.

FINCH, C. F.; BOUFOUS, S. The descriptive epidemiology of sports/leisure-related heat illness hospitalisations in New South Wales, Australia. Journal of Science and Medicine in Sport, Belconnen, v. 11, n. 1, p. 48-51, 2008. http://dx.doi.org/10.1016/j. jsams.2007.08.008. PMid:17931973.

GOLDBERG, S. Descomplicando a fisiologia. Porto Alegre: Artes Médicas, 1997.

GUÉRIN, F. et al. Compreender o trabalho para transformá-lo: a prática da ergonomia. 2. ed. São Paulo: Edgard Blücher, 2004.

HAVENITH, G. Heat balance when wearing protective clothing. The Annals of Occupational Hygiene, Oxford, v. 43, n. 5, p. 289-296, 1999. http://dx.doi.org/10.1093/ annhyg/43.5.289. PMid:10481628.

INTERGOVERNMENTAL PANEL ON CLIMATE CHANGE - IPCC. Summary for policymakers. In: SOLOMON, S. et al. (Ed.). Climate Change 
2007: The Physical Science Basis. Contribution of Working Group I to the Fourth Assessment Report of the Intergovernmental Panel on Climate Change. Cambridge: Cambridge University Press, 2007. p. 1-18.

JUTTEL, L. P. Esforço físico excessivo busca aumento de renda. Ciência e Cultura, São Paulo, v. 60, p. 6-7, 2008.

KJELLSTROM, T.; LEMKE, B.; HYAT, O. Increased workplace heat exposure due to climate change: a potential threat to occupational health, worker productivity and local economic development. AsianPacific Newsletter on Occupational Health and Safety, Helsinki, v. 18, n. 1, p. 5-11, 2011.

KROEMER, K. H. E.; GRANDJEAN, E. Manual de ergonomia: adaptando o trabalho ao homem. 5. ed. Porto Alegre: Bookman, 2005.

LAAT, E. F. et al. Impacto sobre as condições de trabalho: o desgaste físico dos cortadores de canade-açúcar. In: PLATAFORMA BNDES. Impacto da indústria canavieira no Brasil. Rio de Janeiro: BNDES, 2008. p. 36-46.

LAAT, E. F. Trabalho e risco no corte manual de canade-açúcar: a maratona perigosa nos canaviais. 2010. 210 f. Tese (Doutorado em Engenharia de Produção)Universidade Metodista de Piracicaba, Santa Bárbara D’Oeste, 2010.

LAMBERT, M. I.; CHEEVERS, E. J.; COOPOO, Y. Relationship between energy expenditure and productivity of sugar cane cutters and stackers. Occupational Medicine, London, v. 44, n. 4, p. 190194, 1994. http://dx.doi.org/10.1093/occmed/44.4.190. PMid:7949061.

LINHA de Corte. Direção e roteiro: Beto Novaes. Rio de Janeiro: Produção Terra Firme, Video Saúde (FIOCRUZ) e MP2 Produções, 2013. Disponível em: <http:/www.youtube.com/ watch?v=q7aAQeRzGKQ>. Acesso em: 2 jan. 2014.

LUZ, V. G. et al. Consumo alimentar e condições de trabalho no corte manual de cana de açúcar no Estado de São Paulo. Saúde e Sociedade, São Paulo, v. 23, n. 4, p. 1316-1328, 2014. http://dx.doi.org/10.1590/ S0104-12902014000400016.

. Migrant labor and wear-out in manual sugarcane harvesting in São Paulo, Brazil. Ciência \& Saúde Coletiva, Rio de Janeiro, v. 17, n. 10, p. 2831-2840, 2012. http://dx.doi.org/10.1590/S141381232012001000030 . PMid:23099768.

MINAYO-GOMEZ, C. Produção de conhecimento e intersetorialidade em prol das condições de vida e de saúde dos trabalhadores do setor sucroalcooleiro. Ciência \& Saúde Coletiva, Rio de Janeiro, v. 16, n. 8, p. 3361-3368, 2011. http://dx.doi.org/10.1590/S141381232011000900002 .
NOVAES, J. R. P. Campeões de produtividade: dores e febres nos canaviais paulistas. Estudos Avançados, Ribeirão Preto, v. 21, n. 59, p. 167-177, 2007. http:// dx.doi.org/10.1590/S0103-40142007000100013.

OLIVEIRA, F. Trabalho e trabalhadores no Complexo Agroindustrial Canavieiro (os heróis do agronegócio brasileiro). In: ALVES, F. Migrantes. São Carlos: EdUFSCar, 2007. p. 7-9.

POWERS, S. K.; HOWLEY, E. T. Fisiologia do exercício: teoria e aplicação ao condicionamento e ao desempenho. 5. ed. Barueri: Manole, 2005.

RAMOS, P. O uso de mão-de-obra na lavoura canavieira: da legislação (agrária) do Estado Novo ao trabalho superexplorado na atualidade. In: SEMINÁRIO DE HISTÓRIA DO AÇÚCAR: TRABALHO POPULAÇÃO E COTIDIANO, 2., 2007. Itu. Anais... Itu: Editora do Museu Paulista da USP, 2007. Não paginado.

ROBERTS, W. O. Exertional heat stroke: life-saving recognition and onsite treatment in athletic settings. Revista Brasileira de Medicina do Esporte, São Paulo, v. 11, n. 6, p. 329-332, 2005.

RODRIGUES, D. A. Acidentes graves e fatais no trabalho de corte mecanizado de cana-deaçúcar: o olhar através do método MAPA. 2014. 209 f. Dissertação (Mestrado em Saúde Pública)Universidade Estadual Paulista, Botucatu, 2014.

ROGERS, S. Ergonomic design for people at work. New York: John Wiley \& Sons, 1989. v. 2.

SANTOS, S. A. Vigilância em saúde do trabalhador no setor canavieiro no estado de São Paulo. In: ENCONTRO NACIONAL DA RENAST, 5., 2011, Brasília, DF. Anais... Brasília, DF: RENAST, 2011. Não paginado. Disponível em: < http://www.idisa.org.br/ img/File/Apresentacao\%20-\%20Vigilancia\%20em\%20 Saude\%20do\%20Trabalhador\%20no\%20Setor\%20 Canavieiro_Simone\%20Alves\%20dos\%20Santos_2909-11_p.pdf > . Acesso em: 20 ago. 2014.

SÃO PAULO (Estado). Governo do Estado de São Paulo. União da Agroindústria Canavieira de São Paulo. Protocolo de cooperação que celebram entre si, o Governo do Estado de São Paulo, a Secretaria de Estado do Meio Ambiente, a Secretaria de Estado da Agricultura e Abastecimento e a União da Agroindústria Canavieira de São Paulo para a adoção de ações destinadas ao desenvolvimento sustentável da indústria da cana de açúcar no Estado de São Paulo. São Paulo, 4 jun. 2007. Disponível em: < http:// www.ambiente.sp.gov.br/etanolverde/files/2011/10/ protocoloAgroindustriais.pdf $>$. Acesso em: 11 maio 2015.

. Lei n. 11.241, de 19 de setembro de 2002. Dispõe sobre a eliminação gradativa da queima da palha da cana-de-açúcar e dá providências correlatas. Diário Oficial [do] Estado de São Paulo. Brasília, DF, 20 set. 2002. Seção 1, p. 2. 
SERVIÇO DE APOIO ÀS MICRO E PEQUENAS EMPRESAS - SEBRAE. Cadeia produtiva da indústria sucroalcooleira: cenários econômicos e estudos setoriais. Pernambuco: SEBRAE, 2008.

SHAHID, M. S. et al. Echocardiographic and Doppler study of patients with heatstroke and heat exhaustion. The International Journal of Cardiovascular Imaging, Netherlands, v. 15, n. 4, p. 279-285, 1999. http://dx.doi.org/10.1023/A:1006070708952. PMid:10517377.

SILVA, M. A. M. Produção de alimentos e agrocombustíveis no contexto da nova divisão mundial do trabalho. Revista Pegada, Presidente Prudente, v. 9, n. 1, p. 63-80, 2008.

UNIÃO DA INDÚSTRIA DE CANA-DE-AÇÚCAR - UNICA. Área plantada com cana-de-açúcar em 2007-2011. São Paulo: UNICA, 2013a. Disponível em: <www.unicadata.com.br/> Acesso em: 20 fev. 2013.
. Documentos - fotos. São Paulo: UNICA, 2013b. Disponível em: <http://www.unica.com.br/ documentos.php> . Acesso em: 20 fev. 2013.

VILELA, R. A. G. et al. Experiência de vigilância no setor canavieiro: desafios para interromper a "maratona" perigosa dos canaviais. Ciência $\mathcal{E}$ Saúde Coletiva, Rio de Janeiro, v. 19, n. 12, p. 4659-4668, 2014. http://dx.doi.org/10.1590/1413812320141912.12912014.

VILELA, R. A. G.; MACHADO, J. H. Vigilância em saúde do trabalhador e produção acadêmica: uma articulação indispensável; Vigilância do Trabalho Exaustivo, uma alternativa possível? Ciência \& Saúde Coletiva, Rio de Janeiro, v. 16, n. 8, p. 3369-3372, 2011. http://dx.doi.org/10.1590/S141381232011000900003.

WISNER, A. Por dentro do trabalho ergonomia: métodos e técnicas. São Paulo: FTD, 1987. 